\title{
Randomized Double Blind Study for Detecting Association of Globus Pharyngeus with Dietary and Daily Habits of North Indian Population and Formulating a Uniform Treatment Plan
}

\section{Abdul Rehman Khan ${ }^{*}$, Mohammad Aftab ${ }^{2}$, Nizamuddin Sheikh ${ }^{3}$ and Nitin khari ${ }^{4}$}

${ }^{1}$ Associate Professor in Otorhinolaryngology at NIMS, Jaipur NIMS, NH 11C, Delhi Jaipur Expressway, Shobha Nagar, Jaipur, India

${ }^{2}$ Professor JNMC, AMU Aligarh

${ }^{3}$ Professor, Saraswati Medical College Hapur, UP

${ }^{4}$ Resident $P G$, NIMS, Jaipur

*Corresponding Author: Abdul Rehman Khan, Associate Professor in

Otorhinolaryngology at NIMS, Jaipur NIMS, NH 11C, Delhi Jaipur Expressway,

Shobha Nagar, Jaipur, India.
Received: August 12, 2021

Published: August 28, 2021

(C) All rights are reserved by Abdul Rehman

Khan., et al.

\begin{abstract}
Aims: Globus pharyngeus is a painless sensation in throat, described as a foreign body sensation, a tightening or choking feeling. Often associated with persistent clearing of the throat, cough, and change in voice. It makes up 4\% of ENT referrals and is reported to have been experienced by up to $46 \%$ of the population. This study was done to redefine etiological factors and formulate a plan of treatment.

Methods: All the consecutive patients who were having specific symptoms of foreign body sensation, vague pain and discomfort in upper digestive tract or throat were included in this study, during the 3.3 years period from 2018 January. After applying inclusion and exclusion criterias and considering consent for endoscopy 587 patients were included in the study. A uniform questionnaire was devised and all the patients were asked the same questions from the questionnaire and a proforma was filled. Patients were divided in 3 groups in 1:1:1 pattern and Group A was given placebos, Group B was give Treatment regimen as per study and Group C was given Treatment regimen plus psychotherapy, voice/speech therapy and physiotherapy. All the groups were randomized and double blinded. Statistical analysis was performed and fisher exact test and chi square tests were used to detect significance and scope of null hypothesis.

Result: Most common etiological factors involved were repeated dry swallowing of saliva, going to bed late at night and intake of some specific foods which may point to some allergic cause, though it varies from place to place. In $10 \%$ of cases some psychological factor was also responsible. Treatment plan $\mathrm{C}$ was having most significant response, Fisher exact test and chi square tests were done for statistical analysis. The $p$-value is $<0.00001$. The result was significant at $\mathrm{p}<.01$.

Conclusion: Treatment plan B and Treatment Plan C significantly improved symptoms of globus pharyngeus as compared to Plan A (placebo) group.

Keywords: Globus Pharyngeus; Dietary; Daily Habits
\end{abstract}

\section{Introduction}

Globus pharyngeus is a continuous or periodic non-painful sensation of a lump or foreign body in the throat or upper diges- tive tract. In Indian clinical practice it is a common presentation because of specific dietary pattern and daily routine of the patients. Especially in North India this affliction is quite common and is a 
Randomized Double Blind Study for Detecting Association of Globus Pharyngeus with Dietary and Daily Habits of North Indian Population and Formulating a Uniform Treatment Plan

treatment challenge. According to Lee BE., et al. it is a common condition that accounts for approximately $4 \%$ of new referrals to ear, nose and throat (ENT) clinics and it is reported by up to $46 \%$ of apparently healthy individuals, with a peak incidence in middle age.

Gastroesophageal reflux disease (GERD) has been implicated as a major cause of globus [1]. Gastric acid reflux produces number of extraesophageal symptoms in the laryngopharynx, commonly referred to as laryngopharyn-geal reflux (LPR), which include a hoarse voice, cough, a scratchy feeling in the throat, and globus.

Etiology of globus pharyngeus is unclear, some studies suggested it may be caused by increased tone in the upper esophageal sphincter (UES). Tokashiki., et al. have demonstrated that elevated UES pressure resulting from gastroesophageal reflux without direct exposure of the hypopharynx to acid can cause the globus sensation [2].

To recount some specific causative factors this study was planned. As mentioned in various articles worldwide, following etiological factors are associated with globus pharyngeus $[1,3,12,13]$ :

- Gastroesophageal reflux disease

- Abnormal upper esophageal sphincter function

- $\quad$ Esophageal motor disorders

- Pharyngeal inflammatory causes including: pharyngitis, tonsillitis and chronic sinusitis

- $\quad$ Upper aerodigestive malignancy

- Hypertrophy of the base of the tongue

- $\quad$ Retroverted epiglottis

- $\quad$ Thyroid diseases

- $\quad$ Cervical heterotopic gastric mucosa

- $\quad$ Rare laryngopharyngeal tumors

- $\quad$ Psychological factors and stress

- Post surgery (Surgeries like Uvulopalatopharyngoplasty, Uvulopalatoplasty and thyroid surgery) $[4,5]$.

In out patient practice these patients are given multiple variety of treatments but no final uniformly effective treatment plan is mentioned in any internationally followed guidelines. This treatment plan is a trial in this direction to devise a plan which can be used in all diagnosed cases of globus pharyngeus.

\section{Materials and Methods}

From $1^{\text {st }}$ January 2018 to $31^{\text {st }}$ March 2021 all the consecutive patients who presented with following symptoms were analyzed in this study:

- $\quad$ Feeling of something in upper digestive tract.

- Vague pain and discomfort in throat or upper digestive tract.

- Mild to moderate difficulty in swallowing with patient pointing it to upper digestive tract.

Inclusion criteria:

- $\quad$ All the patients with above mentioned symptoms.

- $\quad$ Patients who were ready to undergo barium swallow, transnasal esophagoscopy and upper GI Esophagoscopy upto the Lower Gastroesophageal junction (in some patients).

- $\quad$ Age more than 15 years.

These symptoms were taken as inclusion criteria for the study. All included patients undergone barium swallow, transnasal esophagoscopy and upper GI Esophagoscopy upto the Lower Gastroesophageal junction in some patients complaining of severe symptoms to rule out neoplastic pathology $[6,7]$.

\section{Exclusion criteria:}

- If after investigation some abnormality was detected like congenital defect, malignancy or any neurological deficit patients were excluded and referred to proper speciality or subspecialty.

- $\quad$ Patient aged 15 years or less, (no maximum age limit).

- $\quad$ Patient not giving consent for repeated OPD visits and interviews.

- Patient not giving consent for endoscopy or esophagoscopy or any other investigation.

Cause analysis questionnaire and tables were devised to ask directed questions to gain insight in etiological factors, both dietary and due to daily routine of patient (Appendix I).

Next part of this study was to make a uniform treatment regimen for this disease entity and formulate a standard plan for management. For that after investigations and endoscopic examination patients were divided in three groups in 1:1:1 ratio, first group 
Randomized Double Blind Study for Detecting Association of Globus Pharyngeus with Dietary and Daily Habits of North Indian Population and Formulating a Uniform Treatment Plan

received placebos in the form of multivitamins, second group received:

- Tab melatonin $3 \mathrm{mg}$ once daily at $10 \mathrm{pm}$,

- $\quad$ Cap Rabeprazole plus levosupride empty stomach before breakfast,

- Tab levocetirizine once in the evening,

- Multivitamins capsule once after dinner and,

- Tab Paracetamol 500 mg once daily after lunch,

- $\quad$ Plus steam inhalation everyday morning and evening.

And third group received second Group treatment regimen with psychotherapy, speech and physiotherapy. Full informed consent was taken from patients and their guardians if required.

The study design was double blind, both the patients and observer were unaware which treatment is taken by which group. Naming Treatment A for placebo group and Treatment B and C was used for the medicinal group. Treatment A group was given nearly same no. of tablets/capsules per day as in treatment B group.

Weekly review/follow up of patients was done and symptoms were assessed and noted in a tabular format as shown in table 1.

\begin{tabular}{|l|l|l|l|l|}
\hline $\begin{array}{l}\text { Patient's } \\
\text { Name and R. } \\
\text { no }\end{array}$ & \multicolumn{3}{|l|}{ Ms XYZ [Example] } & $\begin{array}{l}\text { 167XXXX/20 } \\
\text { [Example] }\end{array}$ \\
\hline $\begin{array}{l}\text { Status of } \\
\text { symptom }\end{array}$ & $\begin{array}{l}\text { On } \\
\text { first } \\
\text { visit }\end{array}$ & $\begin{array}{l}\text { On } \\
\text { second } \\
\text { visit } \\
\text { after 1 } \\
\text { week }\end{array}$ & $\begin{array}{l}\text { On third } \\
\text { visit } \\
\text { after } 2 \\
\text { weeks }\end{array}$ & $\begin{array}{l}\text { On last visit } \\
\text { after 4 weeks }\end{array}$ \\
\hline $\begin{array}{l}\text { FB sensation } \\
\text { Pain and } \\
\text { discomfort in } \\
\text { throat }\end{array}$ & +++ & ++ & + & - \\
\hline $\begin{array}{l}\text { difficulty in } \\
\text { swallowing }\end{array}$ & + & - & - & - \\
\hline
\end{tabular}

Table 1: Symptoms based weekly patient entry proforma.

\section{Result}

1326 consecutive patients at our tertiary care centre hospital were seen with the aforementioned inclusion criteria. 39 patients were lost in follow up, 697 not given consent for Endoscopy and barium swallow and 3 patients diagnosed with other GI diseases so they were removed from the study. Thus total 587 patients were included in the study and interviewed as per protocol. Youngest patient was 15 year old and most aged was 81 year old, 49.2 yr was the mean age (Chart 1 ).

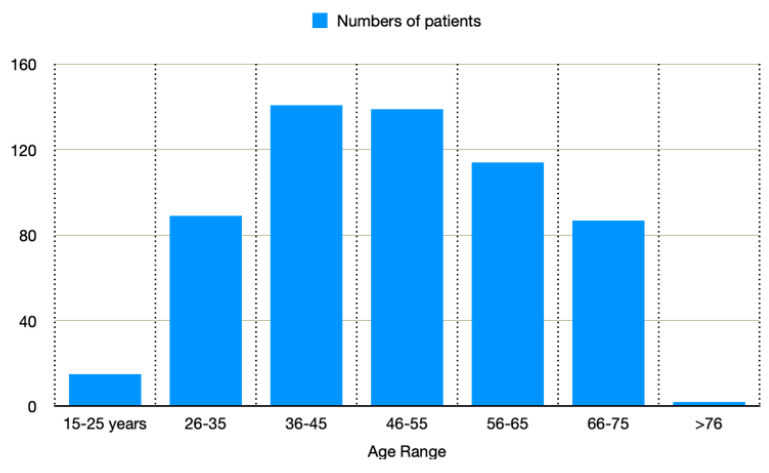

Chart 1: Age range and number of patients with globus pharyngeus patients.

Out of 587, 341 were females and 246 were males, shown in table 2 .

\begin{tabular}{|l|l|l|}
\hline Gender & Number & Percentage \\
\hline Males & 246 & $41.9 \%$ \\
\hline Females & 341 & $58.1 \%$ \\
\hline
\end{tabular}

Table 2: Gender data.

In most of the patients of globus pharyngeus the etiology is multifactorial, as shown in table 3 [7]. In nearly all patients 2 or more etiological factors were present, and most common factors involved were repeated dry swallowing of saliva, going to bed late at night and intake of some specific foods like split black lentils, curd and rice which may point to some allergic cause, though it varied from place to place. In nearly $10 \%$ of patients some psychological factor was involved like death of a close relative by cancer of the upper digestive tract. Such patients were kept in treatment group 3 which included psychotherapy. In few studies a correlation between improvement in GERD symptoms and globus pharyngeus 
Randomized Double Blind Study for Detecting Association of Globus Pharyngeus with Dietary and Daily Habits of North Indian Population and Formulating a Uniform Treatment Plan

$(\mathrm{P}<0.05)$ was found. The improvement in GERD symptoms was greater in patients who reported an improvement in globus pharyngeus than in patients who did not [8].

\begin{tabular}{|l|l|}
\hline Factor & $\begin{array}{l}\text { In Percentage } \\
\text { of patients }\end{array}$ \\
\hline High Salt Intake & 6 \\
\hline Spicy food Intake & 19 \\
\hline Oily food & -- \\
\hline Association with some specific food & 29 \\
\hline Sleep Pattern & 47 \\
\hline Lack of exercise & 42 \\
\hline Smoking & 2 \\
\hline Drinking & 11 \\
\hline Carbonated Cold Drinks & 1 \\
\hline Any diagnosed psychiatric illness & 6 \\
\hline $\begin{array}{l}\text { Death of a family member by cancer of } \\
\text { throat or one family member still dealing } \\
\text { with }\end{array}$ & 9 \\
\hline Snoring & 4 \\
\hline
\end{tabular}

Table 3: Table showing causative factors and their obvious role in the disease.

Also nearly all of the patients were extremely cautious when it comes to taking spicy food, smoking and carbonated cold drinks. Most of them have avoided these things since the beginning of their initial symptoms. But none have corrected their lifestyle and sleep pattern. All education level was uniformly involved, 22 patients were of postgraduate level while remaining were graduates and less educated.
As mentioned in table 4, among the treatment plan A group i.e. placebo group $4.6 \%$ patients reported significant improvement in their, $8.2 \%$ reported moderate improvement, while $26 \%$ patients reported mild improvement in some of their symptoms and $61.2 \%$ reported no change in symptoms. Treatment regimen B showed significant improvement in $17.9 \%$ of patients, moderate improvement in $58.2 \%$ of patients and little improvement in remaining patients. Whereas treatment regimen $\mathrm{C}$ showed significant improvement in $51.8 \%$ of patients, moderate improvement in $39 \%$ of patients and little improvement in remaining patients

Randomization and masking

Eligible patients were randomized and double-blind assessment was done. Clinician assigned to provide treatment Plan was not made aware which plan to use in which patient, and patients were blinded too. Assignment to treatment was via computer-generated random sequence with an interactive web-response system. To preserve blinding, patients in all treatment groups given equal amount of medicines similar in color. Patients in all the treatment groups received equal number of medicines at weekly visits. All patients were counseled to take proper medicines at proper times from the first dose.

Statistical analysis: The target sample size was 587 after applying inclusion and exclusion criterias. We used the Pearson's chi-square test to analyze treatment response after making contingency tables, as in table 4 and 5 . The chi-square statistic is 409.8658 . The $p$-value is $<0.00001$. The result is significant at $p<.01$.

Efficacy outcomes: On the primary endpoint, both treatment plan groups i.e. Group B and C were superior to placebo in the overall mean reduction in the symptoms baseline (Table 4 ). Weekly reduc-

\begin{tabular}{|l|l|l|l|l|l|l|l|l|}
\hline & \multicolumn{9}{|l|}{ After 3 weeks of treatment } \\
\hline Treatment Plan & \multicolumn{2}{l|l|l|l|l|l|l|}{$\begin{array}{l}\text { Significant } \\
\text { Improvement }\end{array}$} & \multicolumn{2}{l|}{$\begin{array}{l}\text { Moderate } \\
\text { Improvement }\end{array}$} & \multicolumn{2}{l|}{$\begin{array}{l}\text { Mild } \\
\text { Improvement }\end{array}$} & \multicolumn{2}{l|}{$\begin{array}{l}\text { Improvement } \\
\text { Improm }\end{array}$} \\
\hline Plan A & 9 & $4.6 \%$ & 16 & $8.2 \%$ & 51 & $26.0 \%$ & 120 & $61.2 \%$ \\
\hline Plan B & 35 & $17.9 \%$ & 114 & $58.2 \%$ & 45 & $22.9 \%$ & 2 & $1.0 \%$ \\
\hline Plan C & 101 & $51.8 \%$ & 76 & $39.0 \%$ & 17 & $8.7 \%$ & 1 & $0.5 \%$ \\
\hline
\end{tabular}

Table 4: Improvement in symptoms by different treatment plans. 
Randomized Double Blind Study for Detecting Association of Globus Pharyngeus with Dietary and Daily Habits of North Indian Population and Formulating a Uniform Treatment Plan

tion in symptoms was statistically different from placebo for both treatment plans B and C starting with week 1 (Chart 2). Over the 3 weeks of treatment, the mean percentages of patients with $\geq 50 \%$ and $\geq 75 \%$ reduction in symptoms were higher for both Group B and $\mathrm{C}$ treatment than for placebo, while treatment plan $\mathrm{C}$ was significantly better than Plan B in reducing symptoms. Some trials have shown improvement in globus symptom scores after a course of speech therapy [9].

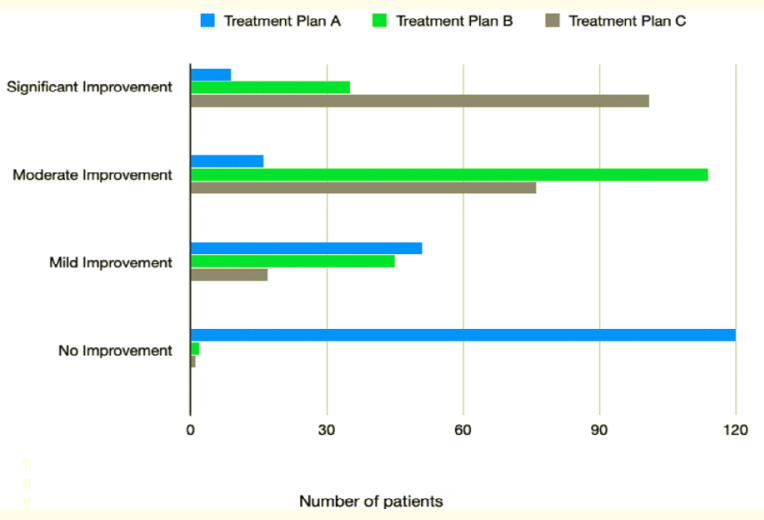

Chart 2: Bar chart showing change in symptoms according to the treatment plan.

For comparing Treatment plan B and C two groups of treatment response were formed. As shown in table 5 first group was patients with significant improvement, which was calculated by adding number of patients having significant and moderate improvement while second group was patients with insignificant improvement, which was calculated by adding number of patients having mild and no improvement. Results were checked using Fisher exact test and Chi Square test. The Fisher exact test statistic value is 0.0002 . The result is significant at $\mathrm{p}<.01$. The chi-square statistic is 14.2837 . The $\mathrm{p}$-value is .000157 . The result is significant at $\mathrm{p}<.01$.

\section{Discussion}

Globus pharyngeus was first recognized by Hippocrates but was first described in 1707 by John Purcell. He said about this condition: "These symptoms are not the vain imaginations and groundless fancies occasioned by the disturbance of the spirits of the brain, but are real sensations actually felt by the patient' [10]. As

\begin{tabular}{|l|l|l|}
\hline & \multicolumn{2}{|l|}{ After 3 weeks of treatment } \\
\hline $\begin{array}{l}\text { Treatment } \\
\text { Plan }\end{array}$ & $\begin{array}{l}\text { Significant } \\
\text { Improvement }\end{array}$ & $\begin{array}{l}\text { Insignificant } \\
\text { Improvement }\end{array}$ \\
\hline Plan A & 26 & 170 \\
\hline Plan B & 149 & 47 \\
\hline Plan C & 177 & 19 \\
\hline
\end{tabular}

Table 5: Significant or insignificant improvement in symptoms by different treatment plans.

prevalence of this condition is high and sensations felt by the patient are real the need to better treat this condition is incumbent. To better diagnose it Rome IV criteria as mentioned in the table 6 was used [11].

\begin{tabular}{|l|l|}
\hline \multicolumn{2}{|l|}{$\begin{array}{l}\text { GLOBUS: Diagnostic criteria*; Must include all of the } \\
\text { following: }\end{array}$} \\
\hline 1 & $\begin{array}{l}\text { Persistent or intermittent, non-painful sensation of a } \\
\text { lump or foreign body in the throat with no structural } \\
\text { lesion identified on physical examination, laryngos- } \\
\text { copy, or endoscopy }\end{array}$ \\
\hline 2 & Occurrence of the sensation between meals \\
\hline 3 & Absence of dysphagia or odynophagia \\
\hline 4 & $\begin{array}{l}\text { Absence of a gastric inlet patch in the proximal esopha- } \\
\text { gus }\end{array}$ \\
\hline 5 & $\begin{array}{l}\text { Absence of evidence that gastroesophageal reflux or } \\
\text { eosinophilic esophagitis is the cause of the symptom }\end{array}$ \\
\hline 6 & Absence of major esophageal motor disorders** \\
\hline $\begin{array}{l}* \text { Criteria fulfilled for the last } 3 \text { months with symptom onset } \\
\text { at least } 6 \text { months prior to diagnosis with a frequency of at } \\
\text { least once a week. }\end{array}$ \\
\hline $\begin{array}{l}\text { **Achalasia/EGJ outflow obstruction, diffuse esophageal } \\
\text { spasm, jackhammer esophagus, absent peristalsis }\end{array}$ \\
\hline
\end{tabular}

Table 6: Rome IV criteria.

This study was done to fulfill two objectives as mentioned earlier.

1. To find frequency of different etiological factors in Globus pharyngeus

2. Devise a treatment plan. 
This study met its primary objective in that both plans of treatment of Globus pharyngeus were superior to placebo in the overall mean reduction of symptoms. There was no previous such study of devising a treatment plan in patients of Globus. Inclusion of psychotherapy, speech therapy and physiotherapy to loosen neck muscles and muscles for vocalization in treatment regimen drastically improved patients symptoms [1,12].

Tricyclic antidepressant Amitriptyline was used by one research group with good results but their sample size was small and secondly in our study psychotherapy was used and medications were kept to a minimum [13].

Rikkunshito, a traditional Japanese medicine, was used by one group of researchers which showed improvement in the globus sensation in patients with PPI-refractory LPR. The improvement may be the result of the stimulation of gastric emptying. Rikkunshito plus PPI therapy may be an effective novel therapeutic strategy for PPI refractory LPR symptoms, including globus sensation and sore throat [2]. Over investigating these patients may add avoidable stress to some of the patients who already seem to have higher levels of depression, anxiety, and other somatic concerns. Authors Kortequee., et al. mentioned that both barium swallow and panendoscopy under GA are things of the past and should not form part of the standard globus assessment [12]. But we have done Barium swallow in our patients to comprehensively diagnose or rule out any neoplasm of the aerodigestive tract and esophagus. As incidence of aerodigestive malignancy is higher in north India [14]. If GERD is present in patients with globus, patients might benefit from PPI therapy by alleviating this potentially aggravating factor (GERD) but, when GERD is absent, empirical treatment with PPI may be misleading and should be avoided [15]. In our study to make a uniform therapeutic regimen we kept PPI in all the patients, also most of the patients who were included in the study were already taking PPI therapy by previous consultations. More research is required in role of PPI in globus pharyngeus.

\section{Conclusion}

Globus pharyngeus is an incessant presentation in OPD of primary care to tertiary care hospitals. Its etiology is not clear; however, GERD and irregular sleep pattern and other factors may play role in some patients. Management of this condition includes reassurance, vocal hygiene, and treatment of reflux if this is appropriate. A planned regimen which includes Rabeprazole, Levosulpride, Levocetirizine, paracetamol, psychotherapy, Speech and language therapy and cognitive behavioural therapy yielded significant results in our study. Association between allergic esophagitis and globus symptoms might be an important topic for further research.

\section{Appendix I}

\section{Questionnaires}

1. Duration of symptoms.

2. Severity of symptoms i.e. how much symptoms are disrupting patients day to day life and routine

3. Education level, categorized into illiterate, upto high school, Intermediate, Graduate, Postgraduate or Professional course.

4. Specific habits in food or daily food intake history with clear pointers on salt, spices, chili and oil levels.

5. Question of daily routine:

- $\quad$ Time to leave bed in morning.

- $\quad$ Specifics of work he/she doing.

- $\quad$ Amount of stress exposed to during work.

- Distance to work and commute taken.

- $\quad$ Exposure to smoke during work.

- Time of lunch, dinner and time after finishing dinner to bed.

- $\quad$ Time to go to bed.

- Hours of sleep taken usually.

- Snoring present or not.

6. Addictions like alcohol intake, smoking, tobacco chewing, tea, coffee quantity during whole day.

7. Television time daily, sitting time and on-couch/bed time other than sleep daily.

8. History of food allergy. (Known allergy or elicited by symptoms).

9. Patient taking any treatment for other conditions.

10. Any deaths or afflictions in family or to close family/friends. 


\section{Appendix II}

\begin{tabular}{|l|l|l|l|}
\hline $\begin{array}{l}\text { Name: } \\
\text { Age/sex: } \\
\text { R. No.: }\end{array}$ & Habit/Dietary additives Intake \\
\hline Habit & Mild & Moderate & Severe \\
\hline & & & \\
\hline Salt & & & \\
\hline Spices & & & \\
\hline Chili & & & \\
\hline Oil & & & \\
\hline Sleep Pattern & & & \\
\hline Stress & & & \\
\hline Addictions & & & \\
\hline GERD & & & \\
\hline $\begin{array}{l}\text { Use of } \\
\text { Medications }\end{array}$ & & & \\
\hline $\begin{array}{l}\text { Any } \\
\text { Psychological } \\
\text { issue }\end{array}$ & & & \\
\hline Notes: & & & \\
\hline
\end{tabular}

\section{Bibliography}

1. Lee BE and Kim GH. "Globus pharyngeus: A review of its etiology, diagnosis and treatment". World Journal of Gastroenterology 18.20 (2012): 2462-2471.

2. Tokashiki R., et al. "Rikkunshito improves globus sensation in patients with proton-pump inhibitorrefractory laryngopharyngeal reflux". World Journal of Gastroenterology 19.31 (2013): 5118-5124.

3. https://patient.info/doctor/globus-sensation-pro\#

4. Franklin KA., et al. "Effects and side-effects of surgery for snoring and obstructive sleep apnea - a systematic review". Sleep 32.1 (2009): 27-36.

5. Consorti F., et al. "Frequency and severity of globus pharyngeus symptoms in patients undergoing thyroidectomy: a pre-post short term cross-sectional study". BMC Surgery 15 (2015): 53.
6. Koufman JA. "The otolaryngologic manifestations of gastroesophageal reflux disease (GERD): a clinical investigation of 225 patients using ambulatory 24 -hour $\mathrm{pH}$ monitoring and an experimental investigation of the role of acid and pepsin in the development of laryngeal injury". Laryngoscope 101 (1991): 1-78.

7. EC Cashman and MJ Donnelly. "The Natural History of Globus Pharyngeus". International Journal of Otolaryngology (2010): 4.

8. R Fass., et al. "Quigley Review article: supra-oesophageal manifestations of gastro-oesophageal reflux disease and the role of night-time gastro-oesophageal reflux". Alimentary Pharmacology and Therapeutics 20.9 (2004): 26-38.

9. HS Khalil., et al. "The use of speech therapy in the treatment of globus pharyngeus patients. A randomised controlled trial". Revue de Laryngologie Otologie Rhinologie 124.3 (2003): 187190.

10. Batch A. "Globus pharyngeus: (PART I)". The Journal of Laryngology and Otology 102.2 (1988): 152-158.

11. https://theromefoundation.org/rome-iv/rome-iv-criteria/

12. S Kortequee., et al. "Management of Globus Pharyngeus". International Journal of Otolaryngo-logy (2013): 5.

13. You LQ., et al. "Effect of low-dose amitriptyline on globus pharyngeus and its side-effects". World Journal of Gastroenterology 19.42 (2013): 7455-7460.

14. Poddar A., et al. "Incidence, prevalence, and mortality associated with head and neck cancer in India: Protocol for a systematic review". Indian Journal of Cancer 56.2 (2019): 101-106.

15. Sinn D., et al. "Response rate and predictors of response in a short-term empirical trial of high-dose rabeprazole in patients with globus". Alimentary Pharmacology and Therapeutics 27.12 (2008): 1275-1281.

\section{Volume 3 Issue 9 September 2021}

(C) All rights are reserved by Abdul Rehman Khan., et al. 